\title{
Author Correction: Nanoparticle conjugates of a highly potent toxin enhance safety and circumvent platinum resistance in ovarian cancer
}

Ruogu Qi, Yongheng Wang, Peter M. Bruno (D), Haihua Xiao, Yingjie Yu, Ting Li, Sam Lauffer, Wei Wei, Qixian Chen (1), Xiang Kang, Haiqin Song, Xi Yang, Xing Huang, Alexandre Detappe (D), Ursula Matulonis, David Pepin, Michael T. Hemann, Michael J. Birrer \& P. Peter Ghoroghchian

Correction to: Nature Communications https://doi.org/10.1038/s41467-017-02390-7, published online 18 December 2017.

This Article contains an error in Fig. 4. In Fig. 4e, the image representing NP was taken from the PBS image. The correct version of Fig. 4 is:

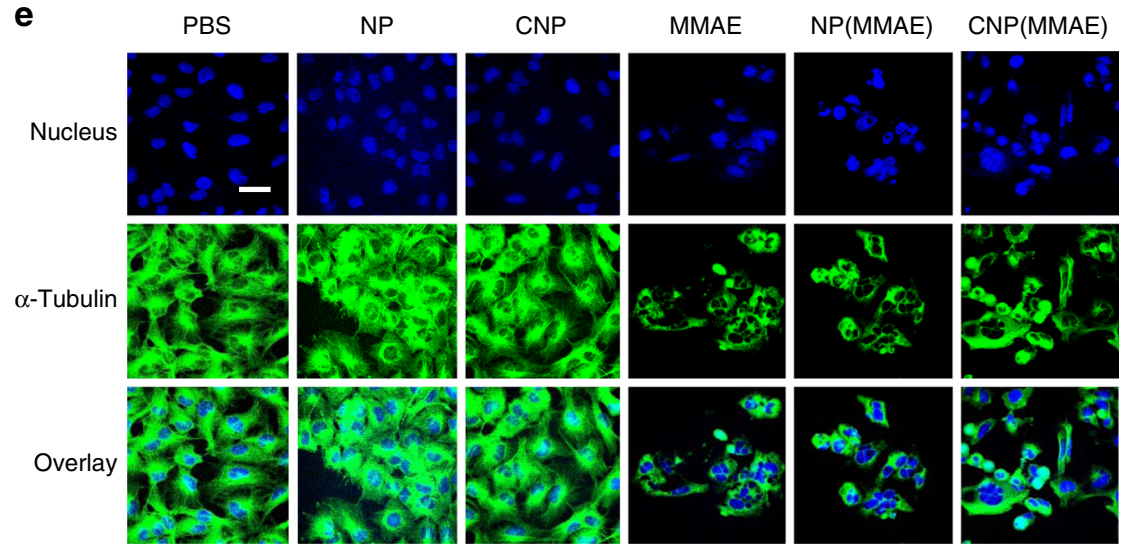

which replaces the previous incorrect version:

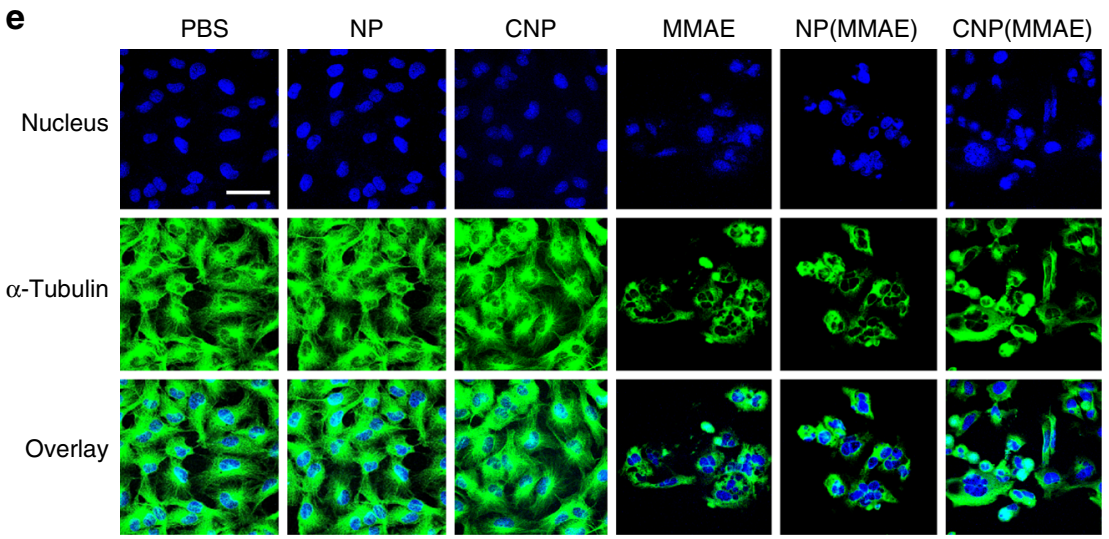

The raw data for the images presented in Fig. 4 can be accessed using the Figshare link https://doi.org/10.6084/m9.figshare.11755248. v1. The error has been corrected in the PDF and HTML versions of the article. 
Published online: 17 April 2020

(c) (i) Open Access This article is licensed under a Creative Commons Attribution 4.0 International License, which permits use, sharing, adaptation, distribution and reproduction in any medium or format, as long as you give appropriate credit to the original author(s) and the source, provide a link to the Creative Commons license, and indicate if changes were made. The images or other third party material in this article are included in the article's Creative Commons license, unless indicated otherwise in a credit line to the material. If material is not included in the article's Creative Commons license and your intended use is not permitted by statutory regulation or exceeds the permitted use, you will need to obtain permission directly from the copyright holder. To view a copy of this license, visit http://creativecommons.org/licenses/by/4.0/.

(C) The Author(s) 2020 